\title{
No Intensive Admit Code for Infants Older than 28 Days
}

Edward A. Liechty, MD

You are receiving in transfer a now 45 day old former 28-week PCA infant (Birth weight $1000 \mathrm{~g}$ ) who was born at a regional Level 4 hospital and required ventilatory management for severe RDS. The infant is now recovered, requiring only $0.5 \mathrm{lpm}$ nasal cannula oxygen flow for occasional apnea/bradycardia spells. His current weight is $1600 \mathrm{~g}$. You are not in the same group practice as the level 4 neonatologists. On admission to your hospital, you perform a complete physical exam and review the ongoing medical issues and plans with the parents. The admission process, including documentation and order completion, takes you 80 minutes; the referring neonatologist sends medical records that require 30 minutes on the day of admission to review.

\section{Correct CPT codes are:}

1. Admit day, 99477, 99356; subsequent days 99479

2. Admit day 99233, 99356; subsequent days 99233

3. Admit day 99223, 99356; subsequent days 99479

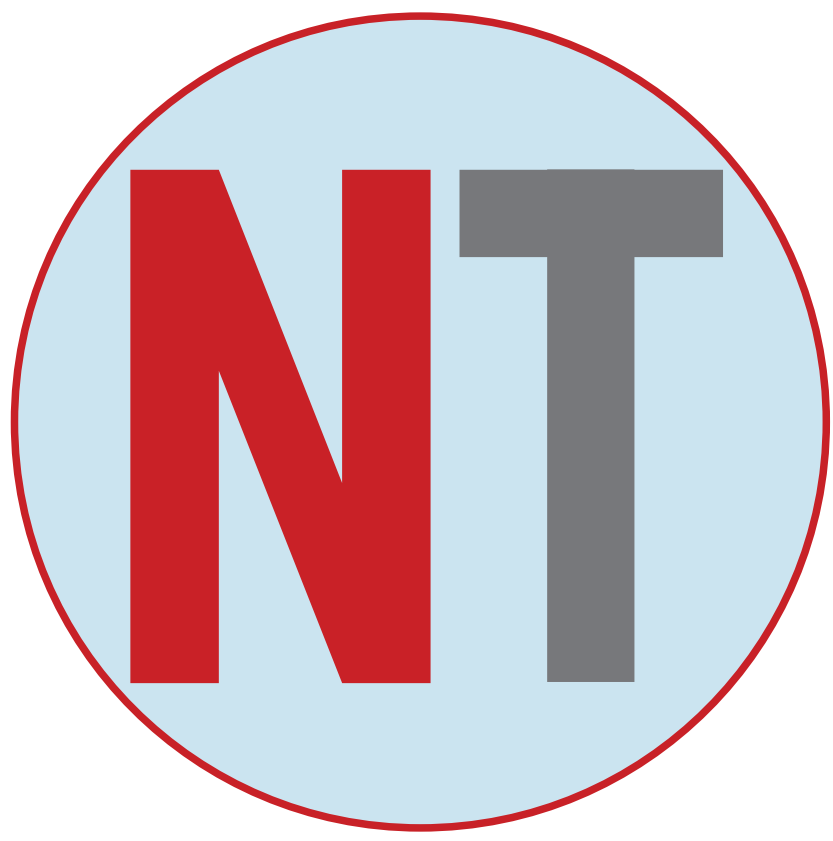

Answer

1. 3.) Admit day 99223, 99356; subsequent days 99479

Even though this infant continues to require intensive care, including continuous cardiac and respiratory monitoring for ongoing apnea, there is no intensive admit code for infants older than 28 days. Therefore, the only option is to use the highest-level hospital initial care code, 99223, which has a typical time of 70 min- utes. Prolonged service time may be added onto the-non-global hospital care codes, provided the total service time exceeds the typical time by at least 30 minutes. In this case, the total time is 100 minutes, so reporting 99356 is justified.

The weight-specific global intensive care codes (99478-80) may be used for subsequent hospital days, even though the infant is older than 28 days, as these are weight but not age-specific. However, if an infant continues to require intensive care after reaching $5000 \mathrm{~g}$, daily hospital care codes (99231-3) must be used.

Answer 1 is incorrect, as 99477 may only be used in an infant less than 29 days of life. Furthermore, 99477 is a global code, and prolonged service codes may not also be reported.

Answer 2 is incorrect as 99233 is for subsequent hospital care services, not initial hospital care services.

ICD-10 codes would include:

P07.14 Other low birth weight newborn, 1000-1249 grams

P07.31 Preterm newborn, gestational age 28 completed weeks

P28.4 Other apnea of newborn

P27.1 Bronchopulmonary dysplasia originating in the perinatal period

\section{"Note that code from Z38.xx Liveborn infants according to the place of birth and type of delivery is not used for this readmission to your hospital, even though it would have been used in the infant's initial care before transfer to the Level 4 unit. The Z38 codes are used only for the initial hospitalization after birth."}

Note that code from Z38.xx Liveborn infants according to the place of birth and type of delivery is not used for this readmission to your hospital, even though it would have been used in the infant's initial care before transfer to the Level 4 unit. The Z38 codes are used only for the initial hospitalization after birth.

\section{References:}

1. International Classification of Diseases. Wolfbane Cybernetic Ltd.. wolfbane.com/icd/index.html. Accessed July 13, 2020.

2. ICD9Data.com.http://www.icd9data.com/2015/Volume1/760-779/764-779/default.htm. Accessed July 13, 2020.

3. ICD10Data.com.https://www.icd10data.com/ICD10CM/ Codes/P00-P96/P05-P08. Accessed July 13, 2020. 
NT

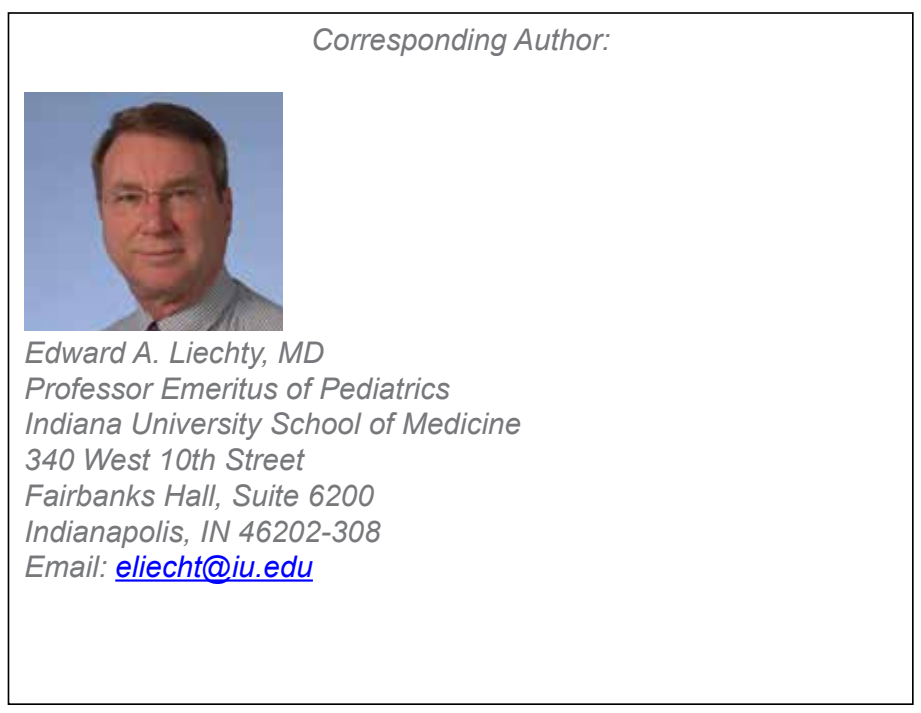

OPIOIDS and NAS

When reporting on mothers, babies, and substance use LANGUAGE MATTERS

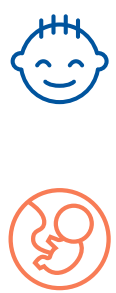

I am not an addict.

was exposed to substances in utero. am not addicted. Addiction is a set of behaviors associated with having Substance Use Disorder (SUD).

I was exposed to opioids.

While I was in the womb my mother and I shared a blood supply. I was exposed to the medications and substances she used. I may have become physiologically dependent on some of those substances.

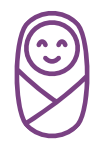

NAS is a temporary and treatable condition.

There are evidence-based pharmacological and non-pharmacological treatments for Neonatal Abstinence Syndrome.

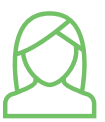

My mother may have a SUD.

She might be receiving Medication-Assisted Treatment (MAT). My NAS may be a side effect of her appropriate medical care. It is not evidence of abuse or mistreatment

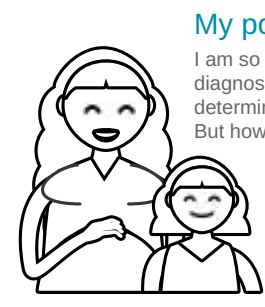

My potential is limitless.

am so much more than my NAS

diagnosis. My drug exposure will not . invest in my family's health and wellbeing by supporting Medicaid and Early Childhood Education you can expect that I will do as well as any of my peers!

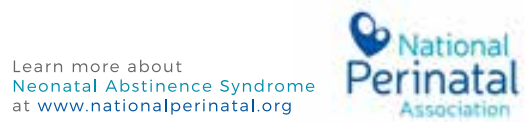

\section{SHARED DECISION-MAKING} PROTECTS MOTHERS + INFANTS

\section{DURING COVID-19}

KEEPING MOTHERS + INFANTS TOGETHER

Means balancing..

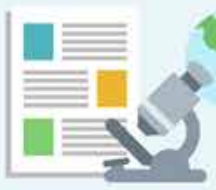

Risk of horizonta infection ॠक

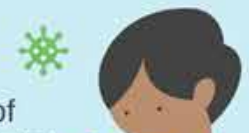
Risks of separation and trauma

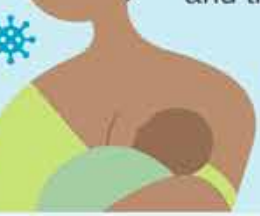

\section{EVIDENCE}

We encourage families and clinicians to remain diligent in learning up-to-date evidence.

\section{PARTNERSHIP}

SHARED DECISION-MAKING

What is the best for this unique dyad?

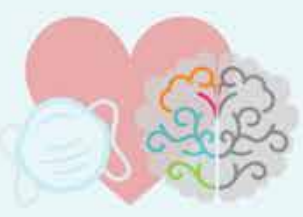

\section{TRAUMA-INFORMED}

Both parents - FEAR and providers - GRIEF are confronting significant...

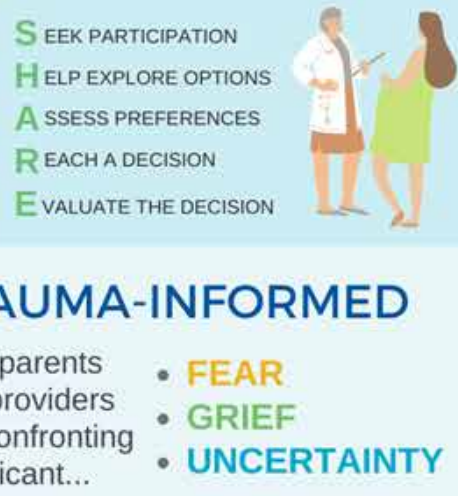

S EEK PARTICIPATION LPEXPLORE OPTIONS - UNCERTAINTY

\section{LONGITUDINAL DATA}

We need to understand more about outcomes for mothers and infants exposed to COVID-19, with special attention to:

\section{- MENTAL HEALTH \\ - POSTPARTUM CARE DELIVERY}

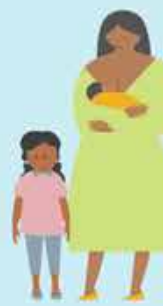

NEW DATA EMERGE DAILY.

NANN AND NPA ENCOURAGE PERINATAL CARE PROVIDERS TO ENGAGE IN CANDID CONVERSATIONS WITH PREGNANT PARENTS PRIOR TO DELIVERY REGARDING RISKS, BENEFITS, LIMITATIONS, AND REALISTIC EXPECTATIONS

Partnering for patient-centered care when it matters most.

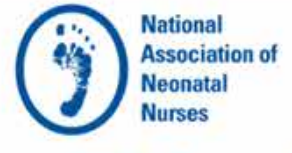

nann.org

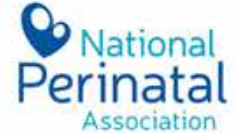

nationalperinatal.org 